\title{
FORMATO ESCUELA VS MAESTRO INVESTIGADOR
}

\author{
FORMAT: SCHOOL VS RESEARCHER TEACHER
}

*Historiador, Magister en Historia, Doctor en Educación; Profesor Titular Universidad Pontitular Universidad Pontitor del Grupo Pedagogía y Didácticas de los Saberes (PDS).

\section{Por: Juan Carlos Echeverri Álvarez*}

Recibido: 11 de febrero de 2016 - Aprobado: 25 de julio de 2016

\section{RESUMEN}

Colombia asume la investigación en la Educación Básica como una estrategia privilegiada para mejorar la calidad de la educación. Con base en una experiencia de formación de docentes, el artículo plantea una hipótesis contraria: la figura del maestro investigador es incompatible con la escuela. La hipótesis se soporta en la categoría Formato Escuela, es decir, la escuela tiene una forma histórica en la cual la investigación, en su modelo científico-universitario, no tiene posibilidad de realización porque es incompatible con ella. Más aún, maestro investigador es una abstracción construida a espaldas de la escuela y, por tanto, no es por la vía de invocaciones, de enjuiciamientos y ni siquiera por la misma formación de los maestros en investigación que se hará realidad esta figura ilusoria; se requiere, mejor, actuar por vías políticas y legales sobre el formato para convertir a la escuela en investigadora, y, una vez lo sea, ella misma convertirá en investigadores a los maestros; el camino inverso, intentar convertir a los maestros en investigadores para que transformen la escuela, será la crónica de un fracaso educativo anunciado, o la suma de propuestas sin más impacto que los objetivos de su propia ejecución.

Palabras clave: escuela, investigación, Colombia, maestro, formato.

\begin{abstract}
In Colombia, research pursued in middle school is seen as a very privileged strategy that is developed in order to improve the quality of education. Based on an training experience of teachers, this article proposes an opposite hypothesis : the figure of the researcher teacher is incompatible with the school. This hypothesis is supported with bases on the category called School Format, this means, the school has a historical background, in which the investigation, following the model scientific-university, does not have a possibility of becoming true because it is incompatible with it. The researcher teacher concept is even seen as an abstraction built at the back of the school and, as a result, it is neither by invocations, prosecutions nor even by the training of the teachers in research processes that this illusive figure will become a reality. It is better required to act by political and legal means on the format to transform the school in a research center. Once it is true, it will transform the teachers into researchers. The reverse path, attempting to change the teachers into researchers for them to transform the school will be the chronicle of an announced educational failure, or the sum of proposals with no more impact than its own objectives.
\end{abstract}

Keywords: school, research, teacher, Colombia, format. 


\section{Introducción}

- a noción "maestro investigador" hace parte del lenguaje "natural" con

el cual se describe en la actualidad la condición ideal de ser maestros en JColombia. Discurso legitimado con la fuerza simbólica de la repetición, con el deseo convertido en invocaciones constantes y con intervenciones más o menos dispersas cuyo objetivo es generar prácticas con algún parecido a los enunciados de esta idea pertinaz. Un discurso que, pese a ciertos destacables esfuerzos, no se confronta con las condiciones de posibilidad histórico-políticas de su realización efectiva ni con prácticas cotidianas que fundamenten desde la propia escuela su existencia real (Ossa y Suárez, 2013:xxiii). Es una idea que fluye por diferentes cauces académicos y gubernamentales hasta convertirse en el sentido común que sirve para explicar lo educativo y pedagógico actual hasta el exceso de convertirse en un obstáculo epistemológico para pensar de otro modo la educación. (Bachelard:1972).

Sin embargo, a los maestros la investigación pareciera servirles mejor para guarecerse de un quehacer vertiginoso en el día a día pero pánfilo en la historia, es decir, investigar es el salvavidas arrojado a maestros que se ahogan entre la apabullante velocidad de las jornadas cotidianas y la lentitud inercial del formato escuela: una estrategia adoptada para mejorar encuadramientos institucionales gracias a las perplejidades de un discurso oceánico que la escuela finge -o desear realmente- acoger pero le es imposible asumir con todas sus consecuencias.

Lo anterior comporta una hipótesis: en Colombia la idea de maestro investigador se ha construido de espaldas a la escuela; y es imposible de realizarla porque se enfrenta con el formato histórico de esta que no tiene la investigación como uno de sus elementos constitutivos. Maestro investigador es una categoría a la cual se le otorga contenido desde arriba hacia abajo, esto es, los docentes universitarios convierten a los maestros de escuela en su alter ego académico sin tener en cuenta las condiciones diferentes de ambos niveles educativos: la investigación encuentra su nicho en una universidad que se ve potenciada por ella; en la Educación Básica es lo contrario: la investigación transita a contrapelo de lo que históricamente ha sido la escuela ${ }^{1}$.

Este argumento encuentra parte de su confirmación empírica en una experiencia de formación de maestros en investigación cuyo éxito inmediato también dejó la evidencia de que en Colombia no se ha pensado de manera detenida la posibilidad real de contar en la escuela con maestros investigadores.
${ }^{1}$ En Colombia el discurso del maestro investigador ha producido reformas desde los años 80 (MEN, 1980), mucho más en la universidad para la formación de pregrado, pero como han dicho pero como han dicho reforma modifica libros, reforma modifica nuevos sistemas de regulación del trabajo académico (...) incorpora nuevas cosmovisiones de la educación pero no está concebida para modificar la institurón escula sis la institucion escuela, surs mecánicas de funcionamiento, sus estructuras
organizacionales" p. 39 
${ }^{2}$ Para conocer detalles de la propuesta ver el libro resultado de la misma: Encuentro consentido pedagógico. Investigación Educativa: un horizonte político de ciudad (2015).
Esta evidencia se traslucía en la perplejidad de los docentes atrapados por el proyecto entre dos lógicas antagónicas: por un lado, un sistema que hace invocaciones, exige excelencia, les nombra investigadores o les inocula este apetito; por el otro, la realidad cotidiana de la escuela constituida por ritmos vertiginosos que exigen presencia, inmersión y acción constante.

El artículo es un aporte para comprender las condiciones de posibilidad que tiene la abstracción maestro investigador de realizarse en las lógicas de un formato escuela que, al mismo tiempo, fomenta la investigación de manera abstracta y la imposibilita de modo concreto. Se organiza del modo siguiente: en primer lugar, sucinta y esquemáticamente, se presenta la propuesta de formación de maestros, mediante la cual se construye la hipótesis señalada; a continuación se despliega la categoría formato escuela y su diferencia con la investigación. Se concluye con la necesidad de tomar una decisión aparentemente paradójica: formar maestros en investigación o transformar la escuela.

\section{Formación en investigación: propuesta y método}

T a propuesta de formación en investigación fue una iniciativa de la Secretaría de Educación de la ciudad de Medellín, en asocio con la Universidad Pontificia Bolivariana, a través del Grupo Pedagogía y Didácticas de los Saberes (PDS). Propuesta cuyas características le auguraban el éxito que efectivamente ha tenido por haber sopesado elementos que, por su ausencia, han hecho fracasar en la escuela intervenciones fundamentadas en la retórica del maestro investigador. ${ }^{2}$ Este no es el espacio para enumerar las bondades de este proyecto, pero es menester decir que la convocatoria misma mezcló el éxito con la preocupación: por los intersticios de su éxito dejaba entrever los obstáculos para producir transformaciones definitivas en la escuela mediante la investigación. Si bien se superó con creces el número de convocados, muchos de los maestros inscritos nunca comenzaron el proceso porque los obstáculos emergentes obligaban a abortar su impulso de participación y el deseo de formarse en investigación.

La satisfacción inicial de los convocantes se fue convirtiendo en preocupación por el aumento de las ausencias parciales, las deserciones definitivas, las quejas y las solicitudes de ayuda para gestionar permisos en las instituciones. Se pasó rápidamente del imperativo de garantizar la calidad académica a la generación de estrategias para sostener a los maestros en el proceso "a cualquier precio". Las indagaciones en torno a los porqués de los abandonos, en todos 
los casos han tenido respuestas referidas al formato escuela, incluso cuando los argumentos se presentaban con la opacidad de: "por motivos personales". Estas respuestas han permitido plantear la oposición entre escuela e investigación $y$, por tanto, hacer visible la imposibilidad actual de contar con el maestro investigador como fundamento de la vida escolar.

Pese a que la propuesta misma no comportaba una metodología en relación con la hipótesis del artículo, se hizo necesario conocer por qué los maestros abandonaban en tan alto número el proceso, o, sin retirarse definitivamente, dejaban de asistir a la mayoría de las sesiones. Se recurrió a elaborar una rejilla para obtener esta información mediante llamadas telefónicas, correos a los pares ${ }^{3}$ y conversaciones directas. Las dos primeras técnicas realmente no presentaron resultados significativos, pues, como estas dejan un registro, las respuestas siempre eran políticamente correctas: -- no tengo tiempo, -- asuntos personales, -- mucho trabajo,--enfermedad, por ejemplo, eran las excusas más comunes. Nos dimos cuenta de que las conversaciones informales eran una fuente de información mucho más rica, fiable y veraz. En ellas, mediadas por la constante solicitud de confidencialidad, los maestros expresaban los verdaderos motivos para su ausencia del proceso: lo que tradujimos como el formato escuela. Con base en esas conversaciones se construyeron una serie de obstáculos que describen las situaciones de los maestros y la lógica de las instituciones frente al tipo de propuestas que le vienen del afuera.

\section{Obstáculos para los maestros investigar en la escuela}

- La investigación como capacitación. Los maestros en retirada, indagados por los motivos, respondían que se habían inscrito en varias cualificaciones para decidir cuál les convenía en una oferta siempre constante. La capacitación, inclusive la cualificación en investigación, es uno de los principales obstáculos para que no se investigue en la escuela. Los maestros son objeto de capacitaciones que nunca alcanzan para transformar su condición ni la estructura de la institución educativa; se inscriben en programas de formación sin más interés que usufructuar estímulos coyunturales con mayores réditos políticos para los patrocinadores que cambios estructurales para la educación. La escuela reconoce la investigación como capacitación sin más consecuencia que un número de horas programadas para gestionar el tiempo de los maestros. Como otras ofertas de cualificación, los cursos de investigación terminan sin más consecuencias que la preocupación por la asistencia regular o por la deserción presumible. Es que:

${ }^{3}$ Par académico era la figura universitaria que figuraba como formador en investigación. El proyecto contaba con ocho pares en el mismo número de líneas de investigación. Ver: Encuentro con-sentido pedagógico. con-sentido pedago Investigación Educativa: un horizonte político de
ciudad. (2015). Medellín. 
${ }^{4}$ Dato de las fichas de inscripción de los docentes. Además, de una prueba diagnóstica sobre competencias en investigación. Ver: informes, 2014, 2015 Inéditos.
La formación continua también necesita condiciones objetivas como tiempo disponible de los participantes, ojalá tiempo remunerado, problema que (...) tampoco se resuelve en la escala de cada escuela y que requiere decisiones normas y recursos originados en los niveles superiores del sistema" (Núñez, 1998, p. 123).\}

- Los maestros no están formados para investigar: verdad de Perogrullo. Además, las competencias investigativas no mejoran significativamente con el nivel académico obtenido. Muchos de los maestros magíster no reconocían más investigación propia que el trabajo de tesis, la cual tiene más sentido formativo que rigurosidad metodológica, y que tampoco cuenta con propósitos de intervención realmente ejecutables ${ }^{4}$. Investigar no es un interés "natural" del maestro porque la escuela termina por convertir la formación avanzada más fácilmente en olvido que en potencia de transformación institucional. Este desconocimiento de lo investigativo, agravado por las deficiencias en escritura y por los obstáculos institucionales, producía una angustia por la cual los maestros decidían retirarse, es decir, no sumar una fuente gratuita de estrés. Así, pues, no saber investigar, ni saber para qué hacerlo, impide investigar a los maestros. Y las condiciones institucionales, por lo general, combaten todo posible contagio de investigación con ungüentos de realidad escolar.

- Sí, hacia afuera; no, hacia adentro. Las directivas escolares se han adaptado mejor que el formato escuela a los tiempos que corren: apoyan las propuestas de formación en investigación con grandilocuente discurso sobre su importancia para mejorar la calidad de la educación. Empero, esta voz que hacia afuera es políticamente correcta, para el adentro de la escuela se convierte en obstáculos para que cada maestro reconozca que debe declinar el impulso de investigar sin menoscabo del compromiso inalterable de las directivas con las propuestas transformadoras de la escuela en las lógicas abstractas del maestro investigador. Los maestros desertaban con una frase impotente pero conciliadora: ime retiro para no tener problemas en la institución! Para las directivas de las escuela era muy importante el proyecto de investigar y de formar en investigación pero, al mismo tiempo, que no se vieran afectados los ritmos institucionales, ni los tiempos y las funciones propias de la jornada laboral, pues, según esas directivas, lo que dejara de hacer un maestro en comisión investigativa lo tenía que asumir otro maestro en función docente.

- Tiempos sin intersticios. Algunos maestros se retiraron, según dijeron, porque las instituciones, al saber de sus comisiones, leyeron que estaban desocupados 
y era menester ponerles a realizar actividades propias de la escuela. El maestro en comisión para investigar en vez de verse desprendido de responsabilidades rutinarias era cargado con tareas emergentes que generaban, según los maestros, un estrés injustificado por asistir a otra "simple capacitación". El tiempo escolar es clase, vigilancia, planeación, atención a los padres, más las incontables contingencias que no pasan por la investigación. Esas contingencias exigen dedicación exclusiva mientras se está en la escuela; el tiempo en ellas no tiene los intersticios de la Educación Superior para la investigación.

- Lógicas de contrajornada: el maestro con inquietudes no contempladas en el formato escuela debe resolverlas por fuera de la jornada laboral. La jornada escolar es para la conservación del formato mismo. La contrajornada, tiempo libre del maestro, es el único tiempo expedito para hacer investigación si el docente tiene esta febril inquietud. ¿Qué otro profesional le llama a su tiempo libre contrajornada? Es como si los maestros usufructuaran un tiempo que realmente no les corresponde $y$, por tanto, en cualquier momento aparece el llamado para pagar su crédito con capacitaciones, demandas a colaborar con la institución, jornadas pedagógicas u otras contingencias. Inclusive los mismos maestros parecieran reconocer esta deuda que les viene con la profesión: los maestros que asistían a las jornadas de trabajo, contagiados por nuestro desconcierto por las ausencias del día, expresaban su solidaridad con una frase desconcertante: irealmente no tienen excusa para faltar: la convocatoria es en contrajornada!

- Escuela sordina de la voz del maestro. La escuela no sabe qué hacer con un maestro que investiga; menos con los productos de investigación: en el mejor de los casos algunas formulaciones precarias se convierten en el producto mismo, pero nada hay entre estas formulaciones y la transformación de las prácticas personales e institucionales. La investigación es innovación, y la escuela todavía opera con las lógicas propias de las instituciones de disciplina y de control (Foucault, 1990; Deleuze, 1995); investigar en la escuela no es innovación sino indisciplina que destruye la unidad general. Además, la investigación de los maestros no tiene el volumen de voz suficiente para hacerse oír en una escuela con déficit de atención para lo que no sea su propio formato. La voz del maestro se expande en una frecuencia casi inaudible para la sociedad; tampoco la escuchan los intelectuales de la educación porque estos, acostumbrados a monologar, han devenido sordos para la rumorosa voz de los maestros, pero con acústica sólo entre los muros de la escuela, a donde el intelectual de la educación no va. 
${ }^{5}$ Decreto 1278 de 2002 art. $5^{\circ}$ : "Las personas que desarrollan labores académicas directa y personalmente con los alumnos de los establecimientos educativos en su proceso enseñanza apren también son respor también son responsables de las actividades curriculares no lectivas complementarias de la función docente de aulo entendidas como ceso educativo, preparación de su tarea académica, investigación de asuntos pedagógicos, evaluacion, calificación, planeación, disciplina y formación de de profes dirección de grupo, actividades formativas, culturales y deportivas, atención a los padres de familia y acudientes, servicio de orientación estudiantil $y$ actividades vinculades con org mos o instituciones del sector que incidan directa o indirectamente en la educación".

'Un número significativo, sin embargo, tiene el deseo y el empeño de ser como dice el discurso que deben ser: investigadores.
- Investigar, enseñar, asear... y otros. Investigar es para el maestro una obligación costosa sin más retribución académica que la desobligante invocación a su propio crecimiento intelectual. La escuela no tiene los recursos para que sus docentes hagan investigación porque su formato no contempla esta función. La investigación de los maestros es cada vez más visible pero sólo en la formación de licenciados (ver: Ossa, 2015). El maestro es investigador mientras se forma en una institucionalidad intrínsecamente investigadora, pero ese perfil no sirve en la escuela más que para utilizarla como estrategia de enseñanza o para desarrollarla a contrajornada. En la escuela la investigación es otra activad nombrada por la ley como una contingencia posible que se exigirá como inherente al cargo en el mismo rango de atender padres, asear salones y cuidar los descansos ${ }^{5}$.

Por tanto, si la investigación del maestro es una lucha contra la institución que lo acoge, si es un espacio que no le da libertad a su tiempo libre, si no tienen recursos y retribución, si no va a tener una comunidad de escucha y unos medios para ampliar su voz, ni un escenario para transformar las prácticas ipara qué, entonces, querría un maestro ser investigador? Preguntas como estas servían de catarsis a maestros que, en último término, reconocían haberse quedado en el proceso con el objetivo de obtener pequeñas ventajas estratégicas de la necesidad gubernamental de invertir en ellos, dentro de la perpleja búsqueda de la excelencia educativa. ${ }^{6}$

\section{Formato escuela vs. investigación}

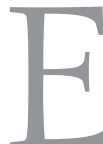

stas reflexiones exigen deslindar las categorías maestro investigador y escuela porque todo intento de relacionarlas de manera efectiva genera un desfase entre lo que se dice y lo que se hace, es decir, deja al descubierto un problema: la primera categoría es una construcción intelectual y, también, una prescripción formulada desde arriba con la intención de transformar la Educación Básica; la segunda anuncia un formato con lógicas de actuación que imposibilitan dentro de ella la realización efectiva de esa prescripción abstracta. La investigación comporta lentitud y exige aislamientos; la escuela vive a velocidad de escape (Dery, 1998), y esa velocidad impide el escape de los maestros para actividades no contempladas de antemano por el formato escuela. La categoría maestro investigador se comporta como un oxímoron: maestro solapa toda la "vertiginosa movilidad" del formato escuela; investigador, por el contrario, exhibe sus necesidades de sustracción, lentitud y aislamiento. El deslinde se hace apremiante porque el discurso de la investigación se ha vuelto hegemónico y fuerza invocaciones reiteradas para que el maestro- 
investigador, se erija en la figura que garantice la excelencia educativa. Empero, las prácticas de investigación de maestros en la escuela producen efectos inesperados que enfrentan a los unos con la otra. Curiosamente, estas evidencias de imposibilidad no desdicen para nada la obcecada idea de que los maestros sean investigadores. Es decir, las experiencias de enfrentamiento no alcanzan a constituir una contradicción insalvable sino la aparentemente obvia connivencia de dos lógicas legítimas: el formato escuela de existencia consuetudinaria, y el maestro investigador como práctica discursiva con experiencias contingentes que no garantizan transformaciones esenciales.

\subsection{Sobre el formato escuela}

“...la proclamación de los fines sociales cada vez más democráticos y la búsqueda de innovaciones pedagógicas cada vez más críticas, hace olvidar que la forma de los edificios, salones, patios, ventanas, rejas y muros donde se encarna ese saber pedagógico cada vez más avanzado, es aún aquella carcaza arcaica cuya estructura (...), no es muy diferente a la de un reformatorio, un cuartel o un hospital. (Saldarriaga, 2006: 64).

Formato remite a la forma de una cosa. Pero argumentar que la escuela tiene una forma no es suficiente para explicar el esquematismo que aparentemente la anquilosa. En efecto, todo tiene una forma, pero al decir formato, y no forma, se destacan las características que funcionan al mismo tiempo como organización y diferencia de un elemento cualquiera. El formato es continente que conserva ciertas características pese a los cambios fortuitos o planeados del contenido: el formato mismo impide cambios radicales en la forma de aquello que contiene porque su función es sujetar bajo una lógica de organización propia. Para la escuela, el formato funciona como un elemento de agrupación inseparable del contenido que, sin embargo, no se confunde con él; es decir, lo condiciona sin determinarlo. El formato escuela es comparable con los diagramas diseñados para presentar proyectos académicos: estructura continente que constriñe la adaptación a ellos de diferentes lógicas de pensamiento, de expresión y de contenido.

El formato escuela es la expresión y el instrumento histórico para concretar ideales de individuo, de maestro, de sociedad y de cultura. Este formato se conserva todavía hoy, con adecuaciones, porque las lógicas que le otorgan vigencia no se han transformado radicalmente desde su emergencia. Es decir, el formato escuela hace parte de una forma que lo desborda al mismo tiempo 
${ }^{7}$ Desde cierta lógica, el Estado es una estrategia del poder liberal para el gobierno de la población mediante dispositivos como la escuela. (ver: Foucault, 2007: para b: noción de dispositivo

nocion ide dispositive Foucault, 1985; Agamben, 2006; Deleuze, 1987; Moro, 2003.

${ }^{8}$ Para la relación histórica entre Educación y Estado, ver: (Varela, 2009).

${ }^{9}$ La invariabilidad es una permanencia que posibilita transformaciones: la constitución es incuestionada e incuestionable, no cambia como forma-

to aunque cambien sus

contenidos y se transforme la sociedad que les otorga legitimidad (Valencia, 1987). que le da inteligibilidad y vigencia: la forma del Estado Constitucional. En esta forma del poder, la escuela adquiere un formato y los maestros, correlativamente, una condición: no hay maestros sin formato escuela pero ellos mismos no son el formato porque este es una adecuación de la forma constitucional del Estado. ${ }^{7}$

Por tal motivo, actuar sobre los maestros, con ellos o para ellos, no transforma el continente; por el contrario, toda actuación y formación terminan adecuadas o invalidadas por él; inclusive, cuando una propuesta de cambio o intervención parece tan drástica como para violentar el formato, el tiempo y el olvido terminan por volverlo a su condición inicial. En otras palabras, para producir cambios fundamentales no se puede ir del formato a la lógica que le otorga vigencia sino de ésta hacia él: de la legalidad a la escuela.

El formato escuela es parte constitutiva del formato constitucional mediante el cual el poder liberal forza su propia transformación, exhaustividad y vigencia. Como la escuela es constitutiva del Estado, no puede comprenderse, juzgarse o proyectarse sino en relación con esta inmanencia histórica insoslayable (Echeverri, 2015). De tal manera, las preguntas necesarias son icuál ha sido la función histórica de la escuela? y, correlativamente, itodavía tiene vigencia esa función? Si la escuela es un dispositivo del Estado, es imposible considerar sus transformaciones sin cambiar también este elemento que le otorga inteligibilidad histórica. En otras palabras, el formato escuela solo es transformable por la vía de los cambios de la forma Estado. ${ }^{8}$

Así, entonces, existe un formato escuela. Este formato se resiste a la idea de instaurar en sus lógicas, ritmos y funciones la presencia de un maestro investigador. Pero no se opone porque sea una especie de esquema fosilizado: "no muy diferente a la de un reformatorio, un cuartel o un hospital", sino porque pertenece, como estos, a una misma lógica invariable por sí misma?: el formato del Estado constitucional en el marco del poder liberal (Foucault, 2007). Para explicar el formato escuela se recurre a cuatro figuras que la forzan a ser lo que todavía es, a contrapelo de discursos y denuncias que intentan reformarla sin éxito: es un esquema legal; vincula íntimamente los maestros con los estudiantes; es una lógica entre muros; establece relaciones particulares con el saber.

- Es un esquema legal: La escuela, como la conocemos desde principios del siglo XIX, es un dispositivo del Estado para el gobierno de la población. La 
Constitución Política fue el símbolo fundacional convertido en condición de posibilidad de cambios en diferentes órdenes de la sociedad: significó el más expedito instrumento para construir una nueva realidad local similar a la civilización occidental, porque la Constitución, como indica su etimología, constituere, establece algo con carácter definitivo, no solamente el Estado, sino la educación y la escuela que son inmanentes al nuevo orden que la constitucionalidad instaura:

La Constitución podría quedar incompleta si no se le añade, como parte conservadora y vivificante, la instrucción pública, a la que sin duda debemos llamar poder, ya que abarca un orden de funciones distintas que deben actuar constantemente en el perfeccionamiento del cuerpo político y en la prosperidad general (Talleyrand, 1791: en Barreiro. 63).

Si la forma constitucional se mantiene vigente en las lógicas de sus propios cambios y reacomodos, la escuela, que le es inmanente, conserva esta misma forma. Decir que la escuela es un formato legal, significa que la legalidad constitucional la estructura con lógicas diferentes a las retoricas intelectuales, los deseos generales e, inclusive, en contra de propuestas emergentes dentro de la misma escuela y de sus maestros. Si las transformaciones buscadas no se fundan en este elemento legal serán construcciones con la resistencia de simples castillos de arena. La retórica académica ha discutido durante más de cien años la figura ilusoria de un maestro investigador, empero, la concreción de esta figura en la escuela seguirá comportando una imposibilidad intrínseca mientras el formato legal insista en que: "los educadores son profesionales que prioritariamente acompañan a los niños, niñas, jóvenes y adultos en su formación integral y en procesos de aprendizaje". ${ }^{10}$

- Adhiere al maestro a la escuela: El encierro que aparenta producir la escuela no es retención sino asimilación. El maestro queda adherido al formato hasta confundirse con él. En este formato el maestro construye su condición como capacidad de mimetizarse con el ambiente, comprenderlo, descifrarlo y potenciarlo. Lo que le da valor como maestro es el estar presente, atento, receptivo, con tacto pedagógico para afrontar la cotidianidad (Manen, 1998: 137). La escuela no se alimenta de lo exterior, como la Universidad, sino de sí misma: de su función histórica con niños que retiene y, al retenerlos, retiene a los maestros que los forman. Estos maestros no son expedicionarios, por el contrario, están situados: su potencia es el anclaje institucional, la adherencia. El sitio y la situación es lo que les otorga su condición. Los maestros se

${ }^{10}$ Borrador de resolución: Por la cual se establecen las características específicas de calidad de los programas de licenciatura en e marco de las condiciones de calidad ciones de calidad para obtener el registro cali-
ficado. MEN. 2015. 
mueven mucho y con rapidez, pero su movimiento más drástico se denomina traslado. En cada sitio, del que se van y al que llegan, su posición es idéntica: se nutre de la capacidad de adaptarse para quedar adheridos. Su desempeño se mide por la capacidad de integrarse hasta dejar de ser visibles dentro de los muros de la escuela.

- Vincula al maestro inextricablemente con los niños: La adherencia a la escuela tiene que ver con otra característica del formato escuela: este forza una relación inextricable entre los niños y los maestros. Se ha dicho, en lógicas retóricas de empoderamiento de los maestros, que el saber pedagógico es la característica que le otorga su condición (Zuluaga, 1987). No es completamente cierto. El problema de los maestros en la escuela no es el saber, este ha estado siempre presente como prescripción en relación con los niños. El mayor o menor vínculo con el saber de los maestros está determinado por la pregunta que estos se formulan en relación con ellos. El maestro seguirá siendo maestro sin el saber pero no lo será sin niños y sin enseñanza. ¿Banalidad? No. En la Universidad, por ejemplo, una lucha constante es cómo ser docente teniendo cada vez menos horas de contacto con estudiantes y más con la ciencia. Para los maestros, los niños son una exigencia que no puede ser obviada en lógicas de saber teórico. Más aún, el mismo saber desdibuja de cierta manera la función maestro.

- Comporta lógicas inteligibles entre muros: La escuela no es una institución de encierro en el sentido de privar de la libertad (Echeverri, 2015: 84). El formato escuela, a diferencia de la prisión que encierra para quitar la libertad, encierra para otorgarla y construirla. Las puertas trancadas de la escuela no son encierro sino acogida: recurso provisional en el cual los niños y jóvenes se guarecen mientras son aptos para habitar de manera definitiva un exterior contingente, azaroso y sin retorno. La escuela encierra el exterior afuera, no a los estudiantes adentro. Además, las puertas cerradas de la escuela no son realmente la división entre el adentro y el afuera: lo es el formato mismo, y este no tiene intersticios ni puertas sino una especie de lógica kafkiana que imposibilita comprender la inviolabilidad de un esquema invisible pero actuante.

Una escuela de puertas abiertas sigue siendo una escuela entre muros. Esto significa que sus lógicas deben ser comprendidas dentro de ellos y actuar en consecuencia. Hasta ahora lo que se ha hecho siempre es leer el adentro como una débil sombra del afuera. Es decir, como si el adentro de la escuela 
tuviera que ser un espejo del exterior y solucionar entre muros lo que la sociedad no es capaz de solucionar afuera: a la escuela le piden comprensión interculturalidad, incorporación de TIC, pensamiento científico y tecnológico, investigación, pero, ipuede tanto esta lógica entre muros? (ver: Cantet, 2008).

\subsection{Investigación: universidad alter ego de la escuela}

I formato investigación tal como ha derivado de la Universidad no es compatible con el formato escuela. Mejor, el formato escuela imposibilita la instauración de la investigación en las instituciones educativas. La primera evidencia de incompatibilidad tiene que ver con el alcance de cada uno de estos formatos: la escuela, pese a que fragua la sociedad (Varela, 1995: 28), comporta una lógica entre muros que produce fenómenos de Reflexión en el sentido físico de ondas emitidas que, dentro de cada institución educativa, se desplazan hasta chocar con las paredes exteriores y se regresan hacia adentro con efectos de eco y de acústica. Construir la sociedad es una misión que requiere de cierto alejamiento, de puertas cerradas, pues, para continuar con metáforas físicas, los fenómenos escolares son de movimiento centrípeto.

La investigación, por el contrario, es intrínsecamente expansiva: se nutre de ondas que en vez de obstáculos, se topa con receptores que la retornan y expanden al mismo tiempo. Es una vocación exhibicionista que se nutre de su propia visibilidad, despliegue y expansión. Formato de lo externo para lo externo. La escuela exige un tipo de Reflexión que es al mismo tiempo acción, movimiento, excitación, rapidez e improvisación. La investigación, su antípoda, es lentitud, reflexión y detenimiento. El formato escuela requiere presencia absoluta, adscripción y adherencia; la investigación requiere sustracción, ausencia, abandono. La investigación siempre sostiene una relación difícil con la docencia, inclusive en la Universidad donde se utiliza, en muchos casos, precisamente para alejarse de esta enseñanza (Borrero, 2004).

La investigación, pese a depender intrínsecamente del método, no es proceso sino producto; lo contrario de la escuela que es puro proceso para un producto contingente y azaroso. La investigación requiere articulaciones entre lo administrativo y lo académico, infraestructura, proyección, réditos tangibles e intangibles, formación y prestigio; en fin, requiere ser una política institucional y gubernamental. Es por esta diferencia de formato que las relaciones universidad escuela son tan complejas: por más acogida, deferencia (o condescendencia, en muchos casos) que se pretenda constituir entre ambas institucionalidades lo cierto es que casi todos los esfuerzos 
terminan por fortalecer, no la relación misma para construir un sistema, sino las particularidades inviolables de dos soledades vecinas (Rilke, carta a Fiedrich Westhoff).

La investigación no es, entonces, una decisión, un remordimiento académico o una prescripción académica que por falta de carácter asumen en tropel los docentes universitarios. Se investiga en la Universidad porque la investigación es un formato impuesto por vía legal, apropiado en políticas institucionales que la forzan en diferentes niveles, intensidades, recompensas y sanciones. La Universidad pasó de un formato en el cual algunos docentes eran investigadores y muchos se dedicaban a la enseñanza a ser un formato en el cual la enseñanza misma produce investigación: una vez la universidad fue presionada para convertirse en investigadora ella forzó a los docentes para que lo fueran (ver: ley 30 de 1992). En cierta forma, el formato investigación en la universidad lo que expresa es: "voy a crear las condiciones para que todos los docentes sean por principio investigadores: séanlo efectivamente". El formato escuela tiene un mensaje un poco diferente: "voy a crear todos los obstáculos para que sean investigadores: séanlo si se atreven".

La investigación requiere unidad y coherencia. En la Universidad se hacen esfuerzos para alcanzar cierto grado de esa coherencia, pues en ella hay exigencia, vigilancia y condicionamientos para investigar porque el Estado se lo exige. Pero en la escuela los pies son de plomo y es Tántalo el corazón (Pombo, 2010): el formato escuela pesa hasta el punto de impedir la movilidad frente a la investigación: apetito cada vez más acentuado que motiva de buena manera las intenciones académicas y personales de los maestros, sin embargo, cada vez que se intenta satisfacer en la escuela esta inclinación de corazón, el propio manjar de la investigación les es retirado con violencia e, inclusive, como lo ha mostrado la experiencia del proyecto, sobre quién se atreven a investigar pende, como en el mito, una enorme piedra de retaliación que le amenaza.

La investigación en Colombia tiene un formato que le ancla de manera definitiva a la Universidad y no a la escuela. Es que cierta lógica cultural separó lo que teóricamente tendría que ser parte de un sistema: la Educación Básica y Superior. A la primera le confirió la obligación de formar rudimentos en lectura, escritura, operaciones, moral y civilidad; a la Superior primero le entregó la obligación de formar las profesiones y, después, de construir el conocimiento científico de las que estas se nutren. La distancia entre uno y otro nivel de la educación se fue tornando abismal: la Educación Superior es 
el camino para producir conocimiento científico, y los docentes universitarios investigadores; escuela es la puerta de la cultura (con puertas cerradas), y los maestros cuidadores con afecto, es decir, que acogen mientras afectan (Brunner, 1997).

Algunas transformaciones en los contextos socioeconómicos internacionales han producido un efecto vertical, de arriba hacia abajo, en la relación que se establece culturalmente entre estos dos niveles de lo que debería ser un sistema educativo: perspectiva desde arriba que convierte al maestro en el alter ego de los docentes universitarios: otro yo que debe por fuerza parecerse a su prestigioso modelo universitario. En los años 80 la Universidad comenzó a forzar la conversión de sus docentes en investigadores e intelectuales. Las facultades de educación emprendieron esa transformación mediante la identificación de un objeto de intervención científica, convertido, al mismo tiempo, en un objetivo político (Echeverry y Zuluaga, 1987). Los maestros de escuela se convirtieron en ese objeto de estudio e intervención a través de una pregunta que enmascara más de lo que explica: ¿por qué los maestros de escuela, como los docentes universitarios, no son también profesionales, intelectuales e investigadores?

La investigación en los niveles Superior y Básico tiene diferentes raseros, y es atravesada por una retórica con efectos perversos en la escuela. La Universidad se ha constituido en la institucionalidad visible socialmente, por tanto, ella misma es responsable del prestigio o de los cuestionamientos de la sociedad. Por esta presencia institucional los docentes universitarios dejan de existir, esto es, la visibilidad institucional invisibiliza a los docentes. No es sobre ellos, como grupo bien delimitado, que recaen las demandas, los enjuiciamientos y las mediciones. La Universidad hace internamente estas cosas para responder corporativamente a la sociedad. Por este motivo, la Universidad es el objeto de actuación, intervención y financiación estatal o privada, y las instituciones de Educación Superior forzan a los docentes a responder por las condiciones que les exigen a ellas. Es una lógica que va de la institucionalidad a los docentes.

La escuela, por el contrario, no existe. Existen los maestros. Pero lo maestros no son la escuela. Ni siquiera todos los maestros más las directivas son la escuela. Cuando se intervienen los maestros, cuando se capacitan, cuando se forman, cuando se les exige, incluso cuando se evalúan, esa acción es sobre los maestros, pero no necesariamente sobre la escuela. La escuela es un formato que no siempre está bien avenido con sus maestros, que los devora, los engulle 
y los normaliza. Un formato que permite, sin embargo, que se experimente en él, que se mueve pero que, como los materiales inteligentes, vuelve a su estado natural pasado poco tiempo. Los maestros están en la escuela y no existen como tales sin este formato que los constriñe, pero el formato mismo se solapa detrás de esta figura ilusoria. Los maestros son una categoría general que atrae las intervenciones, a la que se le demanda y la que se enjuicia, pero a la cual se le quita casi siempre el referente que le otorga su condición: la escuela. En efecto, la escuela no existe pero su formato es inviolable. Darle el tipo de existencia que requiere la investigación tal vez sea el camino para el cambio que se espera del formato escuela.

A su vez, los docentes universitarios no existen como blanco de la prescripción social y gubernamental, existe la Universidad y, por esta existencia, es ella la que tiene que ser de una forma particular que se adecua a los contextos, entre ellos, la necesidad de producir docentes que investigan: la investigación no es en ella una abstracción sino la obligación que el formato Universidad imprime. Esto es, la investigación no va de los docentes a la Universidad sino que esta forza con la investigación la misma posibilidad de habitarla. En la escuela se hace al contrario, gubernamentalmente se insiste en mantener su formato, y se logra, en parte, convirtiendo a los maestros en el blanco del saber-poder, de las responsabilidades, de los enjuiciamientos y de las intervenciones. Así, cuando se menciona la Educación Básica para hacer preguntas fundamentales no se encuentra la escuela para dar la cara pero aparecen los maestros para ser juzgados; en la Educación Superior las mismas preguntas visibilizan la Universidad e invisibilizan a los docentes.

\section{Conclusiones}

\section{Queredlas cual las hacéis o hacedlas cual las buscáis (Sor Juana Inés de la Cruz)}

Como un efecto perverso de la apropiación universitaria de los formatos escuela e investigación, académicos de varios países hace rato vienen haciendo un redescubrimiento que pese a la repetición nunca pierde su potencia original, en parte porque los oyentes todavía fingen asombrarse con lo que realmente es una evidencia grosera: muchos de los maestros formados en investigación, en maestrías y doctorados, quieren abandonar la escuela y pasar a la Universidad como docentes investigadores. Conclusión similar a la del investigador que en un hospital, con una metodología apropiada, descubre en los pacientes dados de alta una tendencia a irse a sus casas. Se exagera con el objetivo de 
mostrar una doble certidumbre: el lugar natural del paciente no es el hospital; recuperar la salud constituye una lógica inviolable que lo forza a irse. La escuela tampoco es el espacio natural de la investigación, por tanto, una vez "contagiados" con este "virus", los maestros desarrollan síntomas que les hace doloroso permanecer en ella.

Para no continuar haciendo estos descubrimientos de Perogrullo es menester pensar detenidamente la relación maestro investigador y formato escuela. Incluso se podrían adaptar las palabras sobre la guerra en Europa del filósofo Ortega y Gasset (1950), en El Espectador: el hecho tremendo de la incertidumbre actual sobre la escuela significa el castigo impuesto a los colombianos por no haber pensado con seriedad, con calma y con veracidad sobre la escuela (271). En vez de actuar como lentos espectadores se toman posiciones y definen políticas por fuera de la escuela. La política pública educativa no puede ir de tumbo en tumbo haciendo caso a cada nuevo descubridor de la fuente eterna de la calidad (García, 2014: 24). Menester es observar y reflexionar para, quizás, llegar a reconocer que el desarrollo del país no se logra por la vía de la Educación Básica sino que el país con voluntad de desarrollo puede mejorar cada vez más su educación en este nivel. Este camino posibilita continuar trabajando en el mejoramiento de la educación sin las perplejidades que atraviesan la pregunta por la escuela.

Maestro investigador es la perplejidad de un sistema educativo que se acostumbró a mirar de arriba hacia abajo, porque cuando institucionalizó el saber experto que hacía ingeniería social, la escuela se quedó con la función de formar ciudadanos, y ella misma se convirtió en objeto de la ciencia universitaria (Popkewitz, 1997). Esta relación tutorial ha ido desdibujando la función histórica de la escuela, por lo menos las lógicas del saber experto, hasta el punto de suponer que la Educación Básica no es el elemento por excelencia de la socialización y la ciudadanía, sino el semillero de la Universidad para la estandarización de la vida como ingeniería e innovación que demanda el liberalismo económico (Rose, 2010). "El fetichismo de la calidad" no permite comprender que la escuela convierte a todos en ciudadanos pero no puede convertir a todos en científicos. ${ }^{11}$ Esa no es su función histórica. Por supuesto la escuela se adecua a las exigencias contextuales pero no puede ser tiranizada hasta el punto de pensar que solo es un defectuoso preámbulo universitario. La escuela es para la vida mucho más que el paso a la Universidad, y para la vida debe ser pensada.

El maestro que pretende ser investigador, en la escuela sufre una pertinaz tensión entre las invocaciones abstractas y las lentas transformaciones.
${ }^{11}$ La idea "Fetichismo de

la calidad" es tomado de (Martínez, 2004, p. 333). 
Tensiones entre una escuela políticamente correcta que responde positivamente al discurso investigador y la imposibilidad de generar prácticas reales de investigación porque el formato no se transforma al mismo ritmo de los discursos que emergen en la superficie de las modas y de las coyunturas. La escuela se aviene con toda nueva convocatoria para maestros, habla de la investigación, la promueve discursivamente, la alienta como superación profesional de los maestros, invita a su realización, capacita, inclusive, en algunos casos, incentiva a los maestros para que investiguen si estos tienen la voluntad real y el gesto desinteresado de hacer investigación... "a contrajornada".

Para ser espectadores atentos y pacientes se deben formular preguntas adecuadas para tomar decisiones y definir políticas: ¿qué es la escuela, qué puede y para qué sirve en la sociedad? (Gvirtz, S; Grinberg, y otros, 2011), ¿debe ser regida por un pensamiento pragmático para alcanzar estándares fijados en otras latitudes?, ¿depende su virtud de producir racionalidades técnico-científicas? Tal vez esta sea la misión actual de la escuela: lograr que los nuevos miembros de la sociedad apropien los valores y las técnicas del presente, es decir, el pensamiento científico-tecnológico, a contrapelo de toda formación, virtud o afecto (Lyotard, 1987). Entonces, con el epígrafe, tenemos que volver a decir: queredlas cual las hacéis o hacedlas cual las buscáis. Es decir, si reconocemos que su formato es distinto al de este tipo de pensamiento, hay que empoderarlas según lo que ya son para la formación humana y social; si se quiere hacer de ellas un espejo de la Universidad, por ejemplo, mediante la instauración de la investigación, es necesario convertirlas por vía gubernamental en eso que se desea. Pero mantener la perplejidad de un discurso que dice sí y unas prácticas que dicen no, es prolongar de manera innecesaria un fracaso constante.

\section{BIBLIOGRAFÍA}

Bachelard, G. (1972). La formación del espíritu científico. Contribución al psicoanálisis del conocimiento objetivo. Buenos Aires, Argentina: Siglo XXI.

Baudelot, Ch. \& Francois L. (2008). Los efectos de la educación. Buenos Aires, Argentina. Del Estante Editorial.

Borrero A. (2004). Educación y política. La educación superior para lo superior y en lo superior. El maestro. Conferencia VI del Simposio Permanente sobre la Universidad.

Brunner, J. (1997). La educación puerta de la cultura. Visor. Madrid, España.

Cantet, L. (2008). Entre muros. París, Francia. 2008. 
Echeverri, J. (2015). Escuela y modelos pedagógicos en clave de gubernamentalidad liberal. Colombia 1821-1946. Medellín, Colombia. UPB.

Echeverri, J. \& Otros. (2015). Encuentro con-sentido pedagógico. Investigación educativa: Un horizonte político de ciudad. Medellín, Colombia. UPB.

Echeverry, A. \& Zuluaga, O. (1987). Las facultades de educación y el movimiento pedagógico. Congreso Pedagógico Nacional. Fecode. Bogotá.

Deleuze, G. (1991). Posdata sobre las sociedades de control. En: Christian Ferrer (Comp.) El lenguaje literario, T. 2, Montevideo. Ed. Nordan.

Dery, M. (1998). Velocidad de escape. Madrid, España: Siruela.

Foucault, M. (1990). Vigilar y castigar. México: Siglo XXI.

Foucault, M. (2007). Nacimiento de la biopolítica. México. Fondo de Cultura Económica.

García, S.; Maldonado, D.; Perry, G.; Rodríguez, C. \& Saavedra, J. (2014). Tras la excelencia docente. Cómo mejorar la calidad de la educación para todos los colombianos. Bogotá. Fundación Compartir.

Gvirtz, S.; Grinberg \& otros. (2011). ¿Para qué sirve la escuela? En: La educación de ayer hoy y mañaba. El ABC de la pedagogía. Buenos Aires, Argentina: Ed. Aique. Capítulo 3. Pp.63-99.

Lyotard, J. F. (1998). La condición postmoderna. Ed. Cátedra, Madrid.

Martínez, Alberto. (2004). De la escuela expansiva a la escuela competitiva: Dos modos de modernización en América Latina. Bogotá: Editorial Anthropos, Convenio Andrés Bello.

Messina, G. (2011). ¿Qué es esto del maestro investigador en América Latina? Actualidades Pedagógicas N. ${ }^{\circ}$ 57. Enero-junio del 2011. Pp. 15-32.

Ortega \& Gasset, J. (1950). El espectador. Madrid, España: Biblioteca Nueva/Almagro 38.

Ossa Montoya, A. (2015). Lo pedagógico y el maestro investigador. Revista Virtual Universidad Católica del Norte, 44, 102-118. Recuperado de http://revistavirtual.ucn.edu.co/index.php/ RevistaUCN/article/view/618/1153

Ossa, A. \& Suárez, J. (2013). El maestro investigador en Colombia. Medellín, Colombia: U de A.

Pombo, R. (2010). La hora de tinieblas. Biblioteca Virtual Universal. Disponible en: http://www. biblioteca.org.ar/libros/211776.pdf

Popkewitz, T. (1997). La profesionalización, el gobierno del profesor y el conocimiento académico: algunas notas comparativas. Revista Interuniversitaria de Formación de Profesorado. No 29. , 89-109.

Saldarriaga, ó. (2006). Del oficio de maestro ¿De intelectual subordinado a experto subordinador? Educación y Ciudad. Bogotá. Idep. N. 1, 53-70. Retrieved from http://www.idep.edu.co/revistas/ index.php/educacion-y-ciudad/article/view/274 
Rose, N. (2010). Powers of freedom. Reframing political thought. London, England: Cambridge.

Talleyrand. (1971). Rapport sur l'instruction publique. En: BARREIRO, H. (2011). Iustración, cahiers, rapports (1730-1799). Apuntes sobre los orígenes de la educación pública contemporánea. Sarmiento. / Núm. 15. pp. 167-180.

Valencia, H. (1987). Cartas de batalla. Una crítica del constitucionalismo colombiano. Bogotá, Colombia: Unal.

Varela, J. (2009), Educación (sociología de la) algunos modelos críticos. En: Román Reyes (Dir): Diccionario Crítico de Ciencias Sociales. Terminología Científico-Social, Tomo 1/2/3/4, Ed. Plaza y Valdés, Madrid-México.

Van Manen, M. (1998). El tacto en la enseñanza. Barcelona. Paidós. 

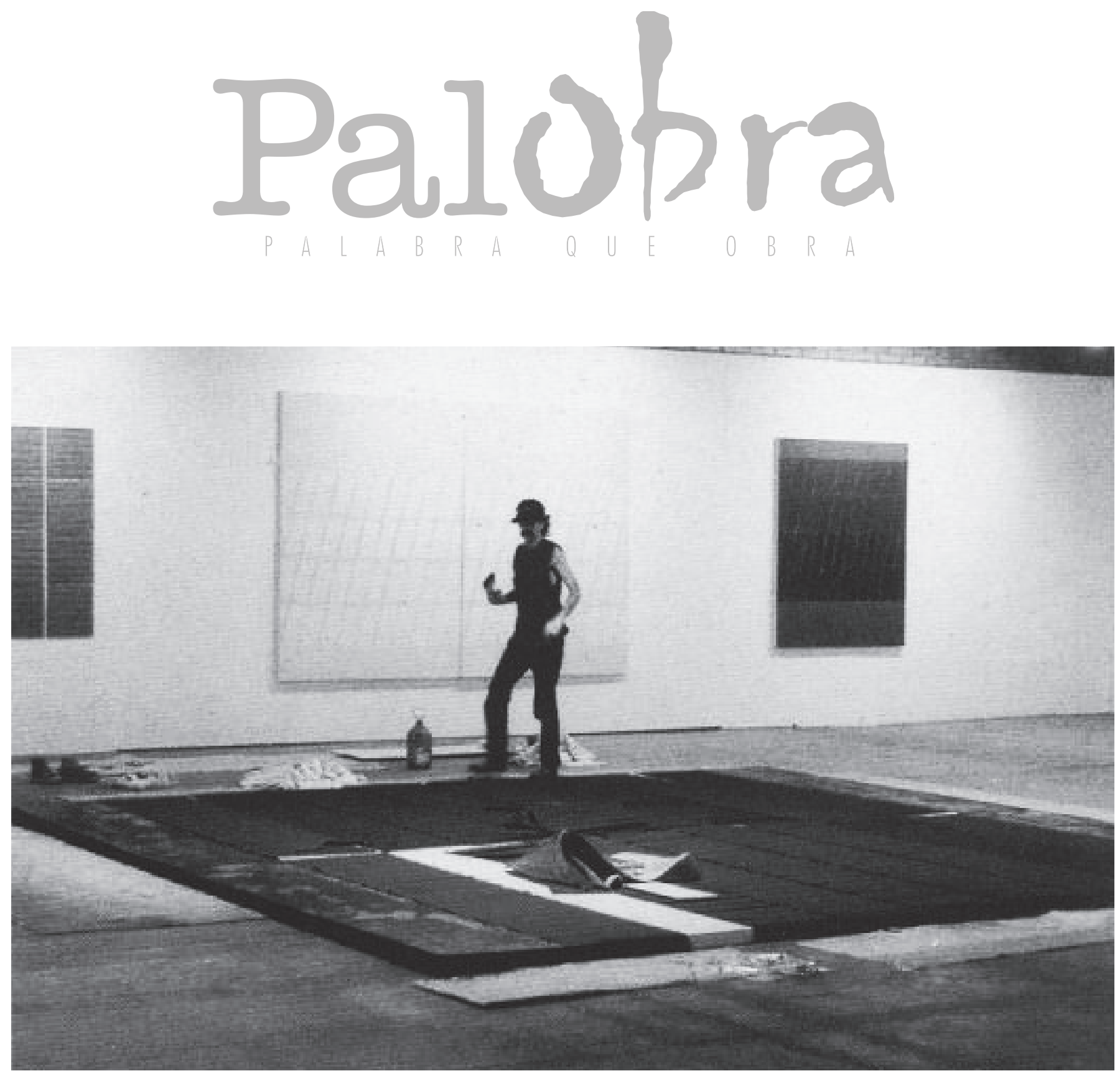

Piscina. 1995.

Instalación. 